\title{
A Systematic Review on the Safety and Efficacy of Blumea balsamifera (L.) DC (NIRPROMP Tablet) for the Treatment of Urinary Tract Stones
}

\author{
Essel N. Tolosa, ${ }^{1}$ Jade P. Rodriguez ${ }^{2}$ and Eliotte Lois F. Malamug ${ }^{2}$ \\ ${ }^{1}$ Institute of Herbal Medicine, National Institutes of Health, University of the Philippines Manila \\ ${ }^{2}$ Department of Industrial Pharmacy, College of Pharmacy, University of the Philippines Manila
}

\begin{abstract}
Objective. To evaluate the safety and efficacy of Blumea balsamifera (L.) DC for the treatment of urinary tract stones.

Methods. Data were collected from online databases, the Philippine National Library, and unpublished clinical trials. We obtained permission from authors of unpublished clinical trials but with existing patent applications. Studies were selected based on the criteria: randomized controlled trials (RCT) on the efficacy of Blumea balsamifera (L.) DC for the treatment of urinary tract stones given alone or in combination with a non-pharmacological/pharmacological intervention in comparison to a pharmacological/non-pharmacological intervention for urinary tract stones with participants aged 15 to 65 years in an ambulatory setting.
\end{abstract}

Results. Our search methods yielded a total of 20 studies. Four studies met our inclusion criteria. Patients who took sambong had a reduction in stone size by radiographic evidence 23.45 times more than those who took the placebo $(p=0.001)$. Also, patients taking sambong were 38.04 times more likely to pass stones compared to those patients taking a placebo $(p=0.0004)$. Patients taking sambong were 7.48 times more likely to have reduction or disappearance of signs and symptoms compared to the placebo group $(p=0.008)$.

Conclusions. Sambong treatment is effective in treating patients with urolithiasis by radiographic evidence of a decrease in size and/or number of stones, the passage of stone/s and/or disappearance or reduction of signs and symptoms with no serious adverse events.

Key Words: Blumea balsamifera L., Sambong, urolitihiasis

Corresponding author: Essel N. Tolosa, RPh

Institute of Herbal Medicine

National Institutes of Health

Room 306 Salcedo Hall

College of Medicine

University of the Philippines Manila

547 Pedro Gil St., Ermita, Manila 1000, Philippines

Email: entolosa@up.edu.ph

\section{INTRODUCTION}

\section{Description of the condition}

Urolithiasis is a condition wherein there is formation of stone/s in the urinary tract. It is frequently termed as urinary tract stone disease and nephrolithiasis. It is a chronic, recurrent condition resulting from different physicochemical, physiologic, and metabolic conditions. It appears more pronounced in industrialized countries. ${ }^{1}$ Renal stone formation and the chemical composition of the stone are age- and gender-dependent. ${ }^{2}$ Urolithiasis occurs in approximately $12 \%$ of the global population and re-occurrence rate in males is $70-81 \%$ compared with $47-$ $60 \%$ in females. ${ }^{3}$ The rate of occurrence in men is three times higher than in women due to enhancing capabilities of testosterone and inhibiting capability of estrogen in stone formation. ${ }^{4}$ The type of stone formed in urolithiasis is named after its mineral composition. Calcium oxalate stones comprise $70 \%$ of all stone formations, $10 \%$ are 
calcium phosphate stones, $5-10 \%$ are uric acid stones, $10 \%$ are struvite stones, and $1 \%$ are cysteine or medicationinduced stones. ${ }^{5}$

Changing lifestyle and dietary choices are the prevalent cause of the increasing incidence of urolithiasis. ${ }^{1}$ Diabetes was also reported in two large epidemiologic studies as an independent risk factor for the development of kidney stones. ${ }^{6}$ Current treatments of urolithiasis are based on the modification of urinary biochemistry and physical chemistry to lower the risk of precipitation of stones. There are drugs available in the market proven to be effective in randomized controlled trials in improving urinary biochemical and physicochemical risk factors. ${ }^{7}$

Medical expulsive therapy (MET) may be utilized to facilitate the passage of the stone/s. MET involves the use of drugs that expel stones. ${ }^{8}$ Calcium channel blockers and alpha-adrenergic blockers have emerged as the most promising agent for MET by relaxing the ureteral smooth muscle through inhibition of calcium channel pumps or blocking the $\alpha-1$ receptor, respectively. ${ }^{8}$ A meta-analysis of nine randomized clinical trials compared calcium-channel blockers or $\alpha$-blockers, with or without corticosteroids, against placebo or no treatment group. The results showed that patients treated with MET were $65 \%$ more likely to pass stones spontaneously compared with the control group (pooled risk ratio 1.65, 95\% CI, 1.45-1.88, $\mathrm{P}<0.0001$ ). Both calcium-blockers and $\alpha$-adrenergic blockers were proved to be effective. ${ }^{9}$ Tamsulosin is one of the most commonly used $\alpha-1$ blocker, however, it is reported in one study that tamsulosin, terazosin, and doxazosin have equal effect indicating possible class effect. ${ }^{10} \mathrm{~A}$ meta-analysis of 11 RCTs with a total of 911 patients reported that patients using $\alpha$-blockers were $44 \%$ more likely of spontaneous stone passage compared with no treatment (risk ratio 1.44, 95\% CI, 1.31-1.58, $\mathrm{P}<0.001) .{ }^{11}$ Nifedipine, a calcium-channel blocker, has also been investigated in facilitating passage of ureteral stones. ${ }^{8}$ Use of tamsulosin and nifedipine is proven safe and effective in patients with urolithiasis, however, tamsulosin is significantly better than nifedipine in relieving renal colic and expediting ureteral stone expulsion. ${ }^{12}$ The American Urological Association/European Urological Association 2007 Ureteral Stones Clinical Guidelines Panel evaluated all available MET trials and pointed out that patients using $\alpha$-blockers resulted in $29 \%$ increase in stone passage rate compared to $9 \%$ in patients using calcium channel blockers. ${ }^{7}$

\section{Description of the intervention (Sambong)}

Sambong has 93 known volatile and 50 non-volatile chemical constituents. ${ }^{13}$ In a modified flow-by dissolution model as an in-vitro chemolytic test for calcium stones, urine from patients that took sambong showed chemolytic effect for calcium stones. Collected urine from individuals who took sambong tablets was passed through an apparatus containing calcium stones that were surgically collected from a patient.
The study showed that urine output of patients who took sambong $(40 \mathrm{mg} / \mathrm{kg} /$ day $)$ gave significant evidence of calcium stone size reduction and increase in calcium concentration of collected urine that passed through the apparatus. ${ }^{14}$ Another in-vitro study identifies urine of patients who took sambong to have a significant reduction in the size of both calcium and uric acid stones. Uric acid stones significantly dissolved faster than calcium stones. ${ }^{15}$ The chemolytic effect on calcium and uric acid stones and the diuretic effect of sambong make it a probable therapeutic agent for urolithiasis. Different preparations of sambong leaves such as expressed juice, decoctions, and powdered, ethanol extract and tablets do not possess direct DNA damaging potential, nongenotoxin before and after metabolic activation, and do not exhibit chromosomal breaking effects. ${ }^{16}$

In the Philippines, sambong is included in the list of 10-recognized medicinal plants and has been clinically proven for use in the treatment of kidney stones and as a diuretic. ${ }^{16}$ The National Integrated Research Program (NIRPROMP) group did clinical studies on sambong and provided the Technological Transfer Document (TTD). Blumea balsamifera leaf tablet is licensed out by the University of the Philippines Manila to local pharmaceutical companies and is listed in the Philippine National Drug Formulary (PNDF) Essential Drugs List under diuretics. ${ }^{17}$

\section{Why it is important to do this review}

Herbal remedies in the Philippines were used since precolonial period. One of the well-studied plants is sambong (Blumea balsamifera (L.) DC.). Sambong was registered under the Food and Drug Administration (FDA) in 1994. Since then, different companies under different brand names have marketed this drug. A systematic review for this drug has not been performed since its registration. This is a pioneer systematic review for this herbal medicine indicated for urinary tract stones. The objective of the study is to evaluate the safety and efficacy of Blumea balsamifera (L.) DC. for the treatment of urinary tract stones.

\section{METHODS}

\section{Included Studies}

We included randomized controlled trials (RCTs) comparing Blumea balsamifera (L.) (DC) leaves with (a) placebo, (b) non-drug treatment, and (c) drug treatment with participants aged $>15$ years with urinary tract stones $>5 \mathrm{~mm}$ in size or with radiographic evidence of urinary tract stones. Studies that included patients with nephrocalcinosis, staghorn calculi, bladder outlet obstruction, and chronic renal disease were excluded from the review. Studies with less than 10 sample size were also excluded.

Primary outcomes measures included were (a) Radiographic evidence of decrease in size or number of stones, (b) Passage of stone/s, and (c) Disappearance or reduction of signs and symptoms. 


\section{Electronic searches}

We searched the Cochrane Central Register of Controlled Trials (CENTRAL) (The Cochrane Library, 1950 to February 2016); MEDLINE (1950 to February 016); PubMed (2004 to February 2016); Elsevier (2004 to February 2016); Journal of Ethnopharmacology (1979 to February 2016); ScienceDirect (2006 to February 2016).

We used the search strategies listed in Appendix I for CENTRAL, MEDLINE, PubMed, Elsevier, Journal of Ethnopharmacology, and ScienceDirect. We initially searched the Philippine Herbs and Supplements Research Database (herbs.ph) but the site was inaccessible.

\section{Searching other resources}

We visited the Philippine National Library and searched their database. We contacted authors of unpublished clinical trials but with existing patent applications. We were able to obtain permission from authors with on-going/ recently ended clinical trials to access their studies to be included in this review. We checked the reference lists of all relevant articles from our searches to identify other possible articles that can be included.

\section{Selection of studies}

Two review authors (JPR, ENT) independently searched and extracted data using the stated search methods. The same two review authors screened and selected the studies according to the stated search criteria. A third author (ELF) resolved disagreements regarding inclusion of studies. The process of selection was documented on Figure 1. Two authors (JPR, ENT) extracted data and entered them into Review Manager 5.3 (RevMan 2013). A third author $(\mathrm{ELF})$ resolved disagreements between the prior authors. (Appendix II Tables 1, 3, 5 and 7)

\section{Assessment of risk of bias in included studies}

Two authors (JPR, ENT) determined the risk of bias for the included studies using Review Manager 5.3 (2013). The studies were assessed based on random sequence generation, allocation concealment, study blinding, selective reporting, and other probable sources of bias. The studies were ranked as low risk, unclear risk, and high risk of bias. (Appendix II Tables 2, 4, 6, 8)

\section{Measures of treatment effect}

We combined the two double-blinded studies and performed statistical analysis in comparing treatment effect for urolithiasis. Treatment effects were measured by tallying the number of patients that had radiographic evidence of decrease in stone size, number of patients that had stone passage, and number of patients with decreased or complete disappearance of signs and symptoms of having urinary stones. We presented a descriptive analysis of the results of the two open-label clinical trials. We considered heterogeneity statistically significant when $\mathrm{I}^{2}$ was $50 \%$ or

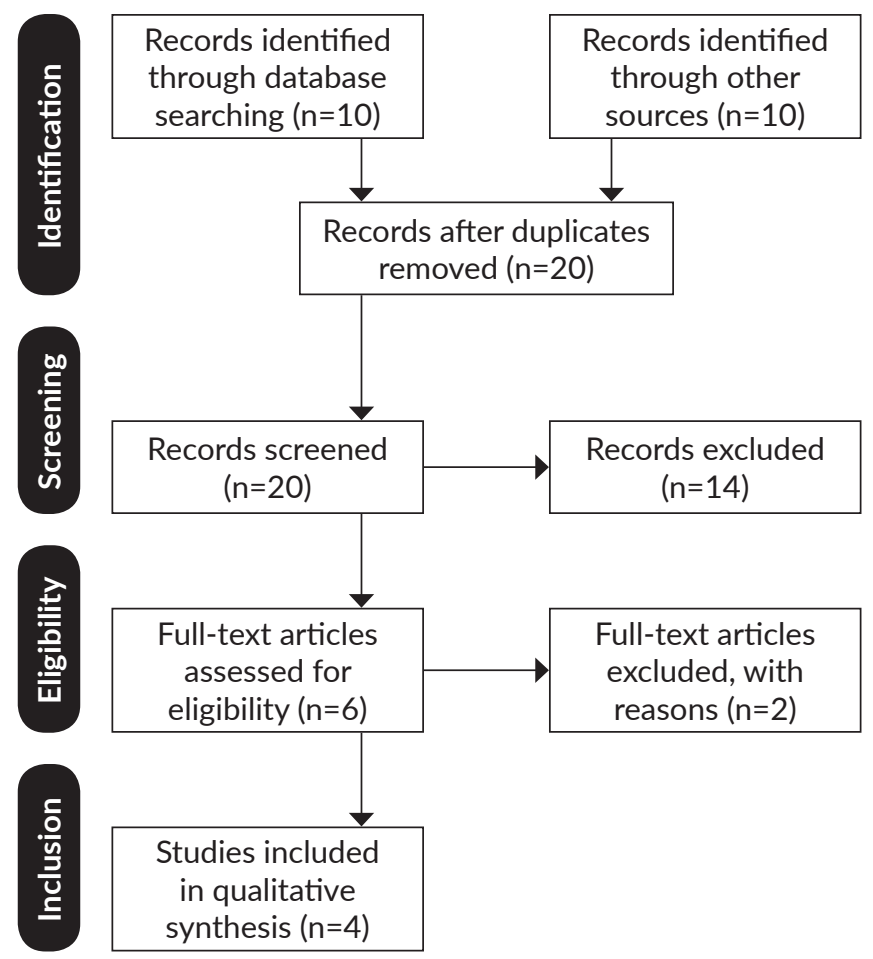

Figure 1. Search Strategy Flow Diagram.

more. We used random effects model for meta-analysis on $\mathrm{I}^{2}$ greater than $50 \%$.

\section{Data synthesis}

We used fixed-effect model for combining data from the two included studies. We used Review Manager 5.3 (RevMan 2013) to perform a Mantel-Haenszel metaanalysis using a fixed-effect method for computation of odds ratio in the occurrence of the treatment effects. Randomeffect method was used for calculation of odds ratio of results with significant heterogeneity.

\section{RESULTS}

\section{Results of the search}

Our search methods yielded a total of 20 studies (10 studies from electronic searches and 10 studies from other sources). Four studies met our inclusion criteria. Two studies were double-blinded studies and two were open-label clinical studies. There was unanimous agreement between the review authors on the inclusion of these four studies. (Figure 1)

\section{Included studies}

We included two double-blinded RCTs (De Leon $1990^{18}$ and NIRPROMP 1994 ${ }^{16}$ ) involving 42 participants in the review. We also included two open-label RCTs (Vergara unpublished ${ }^{19}$ and Bernaldo 200920) involving 131 patients with urinary tract stones. The double-blinded RCT study 
done by NIRPROMP was used as basis for the registration of sambong (NIRPROMP Tablet) in the Philippine FDA as an herbal medicine.

\section{Excluded studies}

In the initial part of our search methods, we selected 10 studies and excluded 6 of them because they (a) were non-clinical study, (b) had different type of outcome measures and, (c) had no pharmacological/nonpharmacological comparison.

\section{Allocation}

The randomization was done using the table of random numbers for studies De Leon (1990), NIRPROMP (1994) and Vergara (unpublished). Participants were assigned to their specific groups by a study coordinator on the basis of the random number table. A research assistant was asked to randomly assign patients in groups in the study of Bernaldo (2009). The studies did not state clearly if there was concealment of allocation sequence.

\section{Blinding}

In De Leon (1990) and NIRPROMP (1994), the study personnel and participants were blinded. There was no form of blinding for Vergara (unpublished) and Bernaldo (2009) since the studies were open-label clinical trial. This could have been a source of detection bias. (Appendix II Tables 2, 4, 6 and 8)

\section{Incomplete outcome data (attrition bias)}

All studies accounted for all dropouts in their respective studies. NIRPROMP (1994) reported that 13 out of 19 participants (68.42\%) completed the study. All dropouts were from the placebo group and none from the sambong group. De Leon (1990) stated no attrition in their study. The study of Vergara et al. had attrition rates of $2 \%$ on both treatment group and control group. Participants were equally divided into treatment and control groups, both groups having one dropout each. Bernaldo (2009) reported 4 dropouts from the initial 31 patients who qualified for the study. Out of the 27 participants who completed the study, 11 participants were assigned to the sambong group, 8 participants to the potassium citrate group, and 8 patients to the placebo group. The study did not state the allocations of the 4 dropouts.

\section{Selective reporting (reporting bias)}

Selective reporting cannot be assessed since we had no access to the study protocols of the clinical trials of the included studies.

\section{Descriptive Analysis of Included Studies}

\section{Efficacy of Sambong}

Vergara et al compared two treatments: sambong tablets with hydration and hydration alone. Sambong with hydration outperformed hydration alone which was statistically significant at $p=0.0000204$ wherein 48 out of 49 patients who took sambong tablets reported spontaneous stone passage as compared to only 30 out of 48 patients in the comparator group. ${ }^{19}$

In 1994, Purificacion reported that 10 out of 18 patients with more than $5 \mathrm{~mm}$ stones who took sambong tablets at $40 \mathrm{mg} / \mathrm{kg} / \mathrm{day}$ for 6 weeks had successful passage of stones and 6 of the other 8 patients had radiographic evidence of decrease in the size of the stones. In this study, 16 out of 18 or $89 \%$ had been completely or partially cured by sambong within 6 weeks. ${ }^{21}$

Bernaldo et al also recorded 10 out of 11 patients who had kidney stones ( $>3 \mathrm{~mm}$ ) who took sambong tablets showed radiographic evidence of decrease in stone size. Eight of these patients recorded complete dissolution of the stones. The sambong treatment showed better outcomes $(p=0.031)$ than the group who took placebo tablets. ${ }^{20}$

\section{Comparison with Potassium Citrate}

Bernardo et al. also compared sambong treatment to a group of patients who received $10 \mathrm{~mL}$ of $10 \%$ potassium citrate 3 times a day. Six out of 8 patients in the potassium citrate group showed radiographic evidence of stone size decrease of which 4 had complete dissolution. The results of the study showed that sambong was comparable with potassium citrate in terms of stone dissolution effect. ${ }^{20}$

\section{Effect on Stone Size}

Hydration alone is as effective as with patients receiving sambong tablet with stone size between 6-7 $\mathrm{mm}$ $(p=0.1411203)$. Vergara et al reported that 23 out of 23 patients (100\%) with stone size between 6-7 mm showed spontaneous stone passage compared to 23 of 26 of patients $(88.5 \%)$ treated with hydration alone. In the same study, 25 out of 26 patients (96\%) with bigger stones (8-10mm) treated with sambong were able to pass urinary stones spontaneously compared with 7 out of 23 patients (30.4\%) treated with hydration alone. ${ }^{19}$

This evidence is based on the number of patients with 6-7mm stones; while $100 \%$ of patients in sambong group showed spontaneous passage, $88.5 \%$ or 23 of 26 patients were also observed with hydration alone. The bigger the stone size of the patients however gives statistical advantage to sambong treatment $(p=0.0000061)$ such that 25 out of 26 patients with $8-10 \mathrm{~mm}$ stones recorded spontaneous passage as compared to only $30.4 \%$ in the patients receiving hydration alone. ${ }^{19}$

\section{Efficacy on Passage Time}

Only the study of Vergara et al. recorded the decrease of passage time of the stones when taking sambong. Passage time for patients with $6-7 \mathrm{~mm}$ and $8-10 \mathrm{~mm}$ stones was reduced to 3.8 and 2.7 weeks, respectively. ${ }^{19}$ 


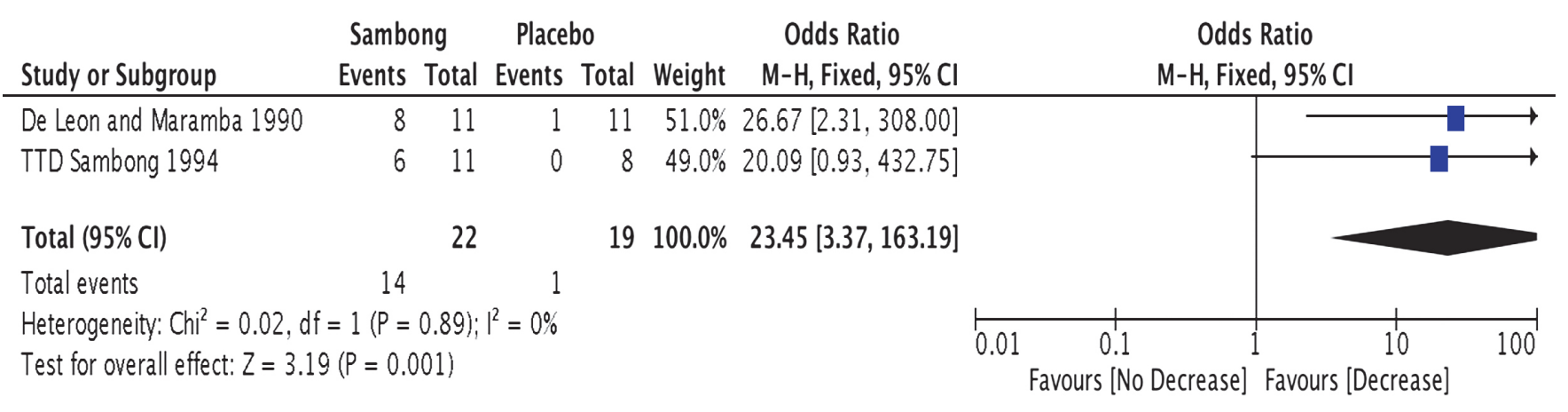

Figure 2. Forrest Plot of Included Studies for Effect of Sambong on Size of Stones.

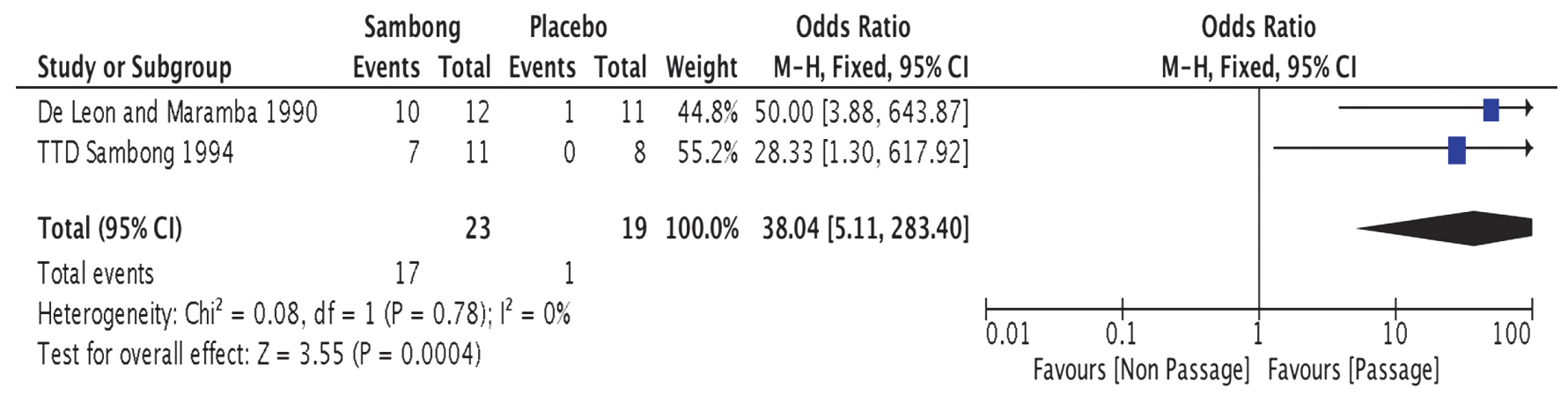

Figure 3. Forrest Plot of Included Studies for Effect of Sambong on Stone Passage.

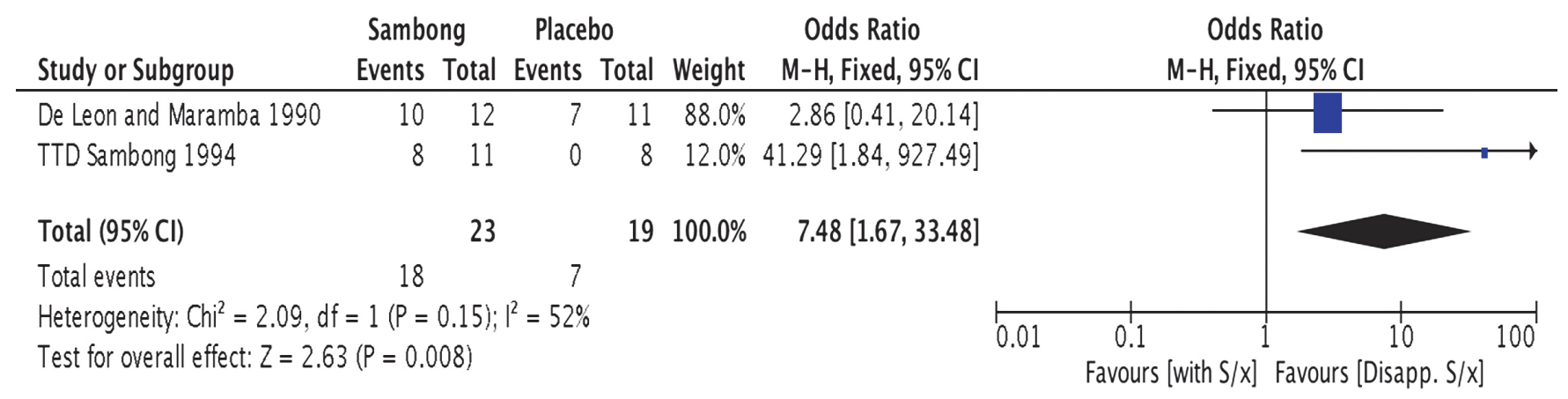

Figure 4. Forrest Plot of Included Studies for Effect of Sambong on Disappearance of Signs and Symptoms.

\section{DISCUSSION}

\section{Pre- and post intervention comparison}

In general, patients who took sambong had reduction in stone size by radiographic evidence 23.45 times more than those who took the placebo. The Forest plot (Figure 2) shows favorable occurrence of the outcome of sambong treatment. Both studies had low heterogeneity between results $\left(\mathrm{Chi}^{2}=0.02, \mathrm{I}^{2}=0 \%\right)$. Sambong treatment had significant effect on stone size reduction compared to the placebo group ( $p=0.001)$.

The results of the combined studies showed that patients taking sambong were 38.04 times more likely to pass stones compared to those patients taking placebo. The Forest plot (Figure 3) indicates the favorable occurrence of stone passage for patients taking sambong tablets. Both studies had low heterogeneity $\left(\mathrm{Chi}^{2}=0.08, \mathrm{I}^{2}=0 \%\right)$. Sambong treatment had significant effect of stone passage as compared with placebo group ( $p=0.0004$ ).

Disappearance or reduction of signs and symptoms of urinary stones between sambong and placebo groups had important variability in the results of the two included studies. A random-effects method was utilized for obtaining the odds ratio due to significant heterogeneity of the results $\left(\mathrm{I}^{2}=52 \%\right)$. The odds ratio of 7.48 was obtained (Figure 4) which indicated that patient taking sambong were 7.48 times more likely to have reduction or disappearance of signs and symptoms compared to the placebo group 
( $p=0.008)$. A summary of findings of comparing sambong to the placebo group for the treatment of uriniary tract stones is presented in Appendix II Table 9.

\section{Recorded Adverse Events}

Only NIRPROMP (1994) recorded adverse reactions of which 2 out of 11 patients experienced mild epigastric pain and constipation without the report of withdrawal from the study. Sambong did not significantly alter urinary and blood biochemical parameters and urinary volume as reported by NIRPROMP. ${ }^{16}$ There were no reported adverse events in other included studies (Appendix II Table 10).

\section{Quality of the evidence}

The included studies presented high risk of bias on allocation sequence concealment. Tablets (placebo, control group and sambong tablets) were not concealed during distribution on the included studies that may contribute to risk of bias. Blinding may also be affected due to nonconcealment of the tablets. Two studies (Bernaldo and Vergara) were open-label clinical trials and could be a source of detection bias.

\section{Agreements and disagreements with other studies or reviews}

There are no other published systematic reviews on sambong for treatment of urolithiasis that has been searched by the authors.

\section{CONCLUSION}

Treatment outcomes, which include radiographic evidence of decrease in size or number of stones, passage of stone/s and disappearance, or reduction of signs and symptoms, of included studies showed favorable occurrence on patients receiving sambong tablets compared with patients receiving placebo tablets. The results of the two double-blinded studies were supported by the results of the two open-labeled clinical trials in which stone passage and decrease in stone size or number of stones was significantly observed in patients receiving sambong treatment. Mild epigastric pain and tinnitus were the adverse events reported in the included studies.

\section{Statement of Authorship}

All authors participated in data collection and analysis, and approved the final version submitted.

\section{Author Disclosure}

All authors declared no conflict of interest.

\section{REFERENCES}

1. Knoll T. Epidemiology, pathogenesis and pathophysiology of urolithiasis. Eur Urol Suppl. 2010; 9(12):802-6.

2. Daudon M, Doré JC, Jungers P, Lacour B. Changes in stone composition according to age and gender of patients: A multivariate epidemiological approach. Urol Res. 2004; 32(3):241-7.

3. Soundararajan P, Mahesh R, Ramesh T, Hazeena BV. Effect of Aerva lanata on calcium oxalate urolithiasis in rats. Indian J Exp Urol. 2006; 44:981-986.

4. Kalpana DV, Baskar R, Varalakshmi P. Biochemical effects in normal and stone forming rats treated with the ripe kernel juice of Plantain (Musa paradisiaca). Anc Sci Life. 1993; 14(3\&4):451-461.

5. Vijaya T, Sahtish Kumar M, Ramarao NV, Naredra Babu A, Ramarao N. Urolithiasis and its causes-Short Review. J Phytopharmacol. 2013; 2(3):1-6

6. Meydan N, Barutca S, Caliskan S, Camsari T. Urinary stone disease in diabetes mellitus. Scand J Urol Nephrol. 2003; 37(1):64-70.

7. Moe O, Pearle M, Sakhaee K. Pharmacotherapy of urolithiasis: evidence from clinical trials. Kidney Int. 2011; 79(4):385-92.

8. Seitz C, Liatsikos E, Porpiglia F, Tiselius HG, Zwergel U. Medical therapy to facilitate the passage of stones: What is the evidence? Eur Urol. 2009; 56(3):455-71.

9. Hollingsworth JM, Rogers MA, Kaufman SR, Bradford TJ, Saint S, Wei JT, et al. Medical therapy to facilitate urinary stone passage: A meta-analysis. Lancet. 2006; 368(9542):1171-9.

10. Yilmaz E, Batislam E, Basar MM, Tuglu D, Ferhat M, Basar H.The comparison and efficacy of 3 different alpha 1-adrenergic blockers for distal ureteral stones. J Urol. 2005; 173(6):2010-2.

11. Parson JK, Hergan LA, Sakamoto K, Lakin C. Efficacy of alphablockers for the treatment of ureteral stones.J Urol. 2007; 177(3):983-7.

12. Gandhi H, Agrawal C. The efficacy of tamsulosin vs nifedipine for the medical expulsive therapy of distal ureteric stones: A randomized clinical trial. Arab J Urol. 2013; 11(4): 405-10.

13. Pang Y, Wang D, Fan Z, Chen X, Yu F, Hu X, et al. Blumea balsamifera-a phytochemical and pharmacological review. Molecules. 2014; 19(7):9453-77.

14. Rico F. Sambong (Blumea balsamifera): its effect on calcium stone. Phil J Urol. 1992; 2(1):9-13.

15. Vinco JSA, Sunga PAL. The use of Blumea balsamifera (Sambong) in the dissolution of urinary stone: An in-vitro study. Phil J Urol. 2006; 16(1): 6-10.

16. NIRPROMP. Blumea balsamifera L. (Sambong) for the treatment of Urinary Tract Stones: A randomized placebo controlled study Phase III Clinical Trial. 1994. Unpublished.

17. DOH-NFC. Philippine National Drug Formulary Essential Drugs List. Vol1, 6th ed. Manila: The National Formulary Committee National Drug Policy Pharma 50 Project Management Unit DOH.

18. De Leon D, Cortes-Maramba N. Blumea balsamifera L. (Sambong) for the treatment of Urinary Tract Stone: A Randomized placebo controlled study Phase III Clinical Trial. Published in the Technology Transfer Document by NIRPROMP and the Philippine Council for Health Research and Development. 1990.

19. Vergara RM, Narciso P, Bardilosa JG. Efficacy of Sambong Tablet in Filipino Patients with Distal 3rd Ureterolithiasis. UERMMMC. 1994. Unpublished.

20. Bernaldo EC, Diwa HA, Marcelo AA, Paps SH, Montemayor ES, Dimacali CD. Comparison of renal stone dissolution effects between potassium citrate and sambong (Blumea balsamifera) - a randomized open label study. Phil J Nephrol. 2009; 23(1):39-42.

21. Purificacion J. Extended Phase III Open clinical trial of Blumea balsamifera L. (Sambong) tablet in the treatment of urinary tract stones. The Filipino Family Physician. 1994; 33(1):17-25.

\section{Funding Source}

None. 


\section{APPENDICES}

\section{Appendix I. Online Database Search Strategies}

\author{
CENTRAL search strategy \\ 1. Blumea balsamifera (38) \\ 2. Urolithiasis (4079) \\ 3. Sambong (0) \\ 4. 1 and $2(0)$ \\ 5. 2 and $3(0)$ \\ 6. 1,2 and $3(0)$
}

\section{MEDLINE search strategy}

1. Blumea balsamifera (7)

2. Urolithiasis (189)

3. Sambong (0)

4. 1 and $2(2)$

5. 2 and $3(0)$

6. 1,2 and $3(0)$

\section{PubMed search strategy}

1. Blumea balsamifera (38)

2. Urolithiasis $(35,420)$

3. Sambong (4)

4. 1 and $2(1)$

5. 2 and $3(0)$

6. 1,2 and $3(0)$

\section{Elsevier search strategy}

1. Blumea balsamifera (0)

2. Urolithiasis $(3,340)$

3. Sambong $(0)$

4. 1 and $2(0)$

5. 2 and $3(0)$

6. 1,2 and $3(0)$
Journal of Ethnopharmacology search strategy

1. Blumea balsamifera (30)

2. Urolithiasis (57)

3. Sambong (0)

4. 1 and $2(2)$

5. 2 and $3(0)$

6. 1,2 and $3(0)$

\section{ScienceDirect search strategy}

1. Blumea balsamifera (77)

2. Urolithiasis $(10,335)$

3. Sambong (25)

4. 1 and 2 (5)

5. 2 and $3(1)$

6. 1,2 and $3(0)$

\section{Appendix II. Characteristics of Included Studies}

Table 1. Characteristics of Bernaldo 2009

\begin{tabular}{|c|c|}
\hline Methods & Randomized Open Label Clinical Trial \\
\hline Participants & $\begin{array}{l}31 \text { Patients }>19 \text { years old with non obstructing stones regardless of size; exclusion: Patients with Chromium chloride } \\
<30 \mathrm{ml} / \mathrm{min} \text {, on thiazide diuretics, hyperkalemia }>5.6 \text {, hypocalcemia }\end{array}$ \\
\hline Interventions & $\begin{array}{l}\text { Random assignment to either Sambong }(500 \mathrm{mg} 2 \mathrm{x} / \text { day for at least } 2 \text { days or Potassium Citrate } 20 \% \text { solution } 10 \mathrm{~mL} 3 \times / \text { day } \\
\text { for } 2 \text { months or placebo similar to sambong } 2 \text { tablets } 3 x / \text { day for } 2 \text { months; follow-up at } 1 \text { month, } 2 \text { months and } 3 \text { months. } \\
\text { On follow-up report }\end{array}$ \\
\hline Outcomes & $\begin{array}{l}8 \text { out of } 11 \text { Patients from the Treatment (Sambong) Group, } 4 \text { out of } 8 \text { Patients from the Positive Control Group } \\
\text { (Potassium Citrate), and } 2 \text { out of } 8 \text { Patients from the Negative Control (Placebo) Group showed Disapperance of stone } \\
2 \text { out of } 11 \text { Patients from the Treatment (Sambong) Group, } 2 \text { out of } 8 \text { Patients from the Positive Control Group } \\
\text { (Potassium Citrate), and } 1 \text { out of } 8 \text { Patients from the Negative Control (Placebo) Group showed Decrease in size of stone }\end{array}$ \\
\hline
\end{tabular}

Table 2. Risk of Bias Table for Bernaldo 2009

\begin{tabular}{lll}
\hline Bias & Authors' judgement & Support for judgement \\
Random sequence generation (selection bias) & Low risk & Use of table of random numbers \\
Allocation concealment (selection bias) & High risk & Open Label Study (Tablets were not concealed) \\
Blinding of participants and personnel (performance bias) & Low risk & Personnel and Patients were not blinded \\
Blinding of outcome assessment (detection bias) & Low risk & Open Label study increases detection bias \\
Incomplete outcome data (attrition bias) & Low risk & Proper documentation of attrition was done \\
Selective reporting (reporting bias) & Low risk & All data outcomes were measured and reported. \\
Other bias & Unclear risk & N/A \\
\hline
\end{tabular}

Table 3. Characteristics of De Leon 1990

\begin{tabular}{ll}
\hline Methods & RCT \\
\hline Participants & $\begin{array}{l}25 \text { patients aged 15-60 y/o with radiographic evidence of urinary tract stones with good renal function; exclusion: chronic } \\
\text { renal disease, gout, asthma, CHF class III, uncontrolled DM, blood dyscrasia, no diuretics, allopurinol, acetazolamide or } \\
\text { diuretics within } 2 \text { weeks }\end{array}$ \\
\hline Interventions & $\begin{array}{l}\text { Random assignment to placebo or sambong group; baseline labs- CBC, FBS, BUN, creatinine, electrolytes, Uric Acid, Calcium, } \\
\text { 24-h urine collection. }\end{array}$ \\
\hline Outcomes & $\begin{array}{l}\text { 8 out of } 11 \text { patients have radiographic evidence of decrease in size or number of stones } \\
\text { 3 out of } 12 \text { patients has complete passage of stone and disappearance of signs and symptoms } \\
\text { 7 out of } 12 \text { patients increased passage of stones and disappearance or reduction of signs and symptoms } \\
10 \text { out of } 12 \text { global evaluation complete cure / partial cure } \\
\text { O out of } 12 \text { showed no evidence of passage of stones or disapperance or reduction of signs/symptoms } \\
\text { 1 out of } 12 \text { had Epigastric pain episode. } \\
\text { 0 out of } 12 \text { had Tinnitus. }\end{array}$ \\
\hline
\end{tabular}


Table 4. Risk of Bias Table for De Leon 1990

\section{Bias}

Random sequence generation (selection bias)

Allocation concealment (selection bias)

Blinding of participants and personnel (performance bias)

Blinding of outcome assessment (detection bias)

Incomplete outcome data (attrition bias)

Selective reporting (reporting bias)

Other bias
Authors' judgement Support for judgement

Low risk

High risk

Low risk

Low risk

Unclear risk

Low risk

Unclear risk

Table 5. Characteristics of NIRPROMP 1994

\begin{tabular}{|c|c|}
\hline Methods & RCT \\
\hline Participants & $\begin{array}{l}\text { 15-60 y/o with urinary tract stones }>5 \mathrm{~mm} \text { on excretory urogram or renal ultrasound with good renal function. } \\
\text { exclusion: nephrocalcinosis, staghorn calculi, and bladder outlet obstruction, chronic renal disease, gout, asthma, CHF class III, } \\
\text { uncontrolled DM, blood dyscrasias; no diuretics, allopurinol, acetazolamide, or diuretics within } 2 \text { weeks }\end{array}$ \\
\hline Interventions & $\begin{array}{l}\text { Randomly assigned to placebo or sambong group; baseline labs-CBC, FBS, BUN, Creatinine, electrolytes, UA, Calcium, } \\
\text { 24-h urine collection instructed to eat their usual diet, increase liquids to } 3 \text { liters per day } \\
\text { Sambong group given } 40 \mathrm{mg} / \mathrm{kg} / \mathrm{day} \text {. } \\
\text { Placebo group same amount of tablets. Followed up on day 4, day 7, week } 2 \text { and week } 4 \text {. }\end{array}$ \\
\hline Outcomes & $\begin{array}{l}6 \text { out of } 11 \text { patients have radiographic evidence of decrease in size or number of stones } \\
1 \text { out of } 11 \text { patients has complete passage of stone and disappearance of signs and symptoms } \\
6 \text { out of } 11 \text { patients increased passage of stones and disappearance or reduction of signs and symptoms } \\
8 \text { out of } 11 \text { global evaluation complete cure/ partial cure }\end{array}$ \\
\hline
\end{tabular}

Table 6. Risk of Bias Table for NIRPROMP 1994

\section{Bias}

Random sequence generation (selection bias)

Allocation concealment (selection bias)

Blinding of participants and personnel (performance bias)

Blinding of outcome assessment (detection bias)

Incomplete outcome data (attrition bias)

Selective reporting (reporting bias)

Other bias

\section{Authors' judgement Support for judgement}

Low risk Use of table of random numbers

High risk Tablets were not completely concealed.

High risk High probability of identifying the difference of tablets

due to incomplete allocation concealment.

High risk High probability of identifying the difference of tablets due to incomplete allocation concealment.

Low risk All dropouts recorded. Outcomes were easily recorded.

Low risk All data outcomes were measured and reported.

Unclear risk N/A

Table 7. Characteristics of Vergara (Unpublished)

\begin{tabular}{|c|c|}
\hline Methods & Random Open Label Comparative Controlled Study \\
\hline Participants & Adults with distal 3rd ureterolithiasis with calculi measuring 6-10 mm; normal serum creatinine \\
\hline Interventions & $\begin{array}{l}\text { Patients were randomly assigned to Sambong + Hydration Group (Treatment) or Hydration Only Group (Control). } \\
\text { The Sambong + hydration group was given } 2500 \mathrm{mg} \text { tablets } 3 x / \text { day with Hydration of } 2.5 \mathrm{~L} / \text { day) while the Hydration Only } \\
\text { group was given } 2.5 \mathrm{~L} / \text { day. Follow up was done for } 16 \text { weeks. }\end{array}$ \\
\hline Outcomes & $\begin{array}{l}48 \text { out of } 50 \text { patients from the Treatment Group had Spontaneous stone passage in } 8 \text { weeks while } 30 \text { out of } 50 \text { patients from } \\
\text { the Control group had Spontaneous stone passage in } 16 \text { weeks } \\
23 \text { out of } 23 \text { patients from the Treatment Group while } 23 \text { out of } 26 \text { patients from the Control Group had Spontaneous Stone } \\
\text { passage (6-7 mm stone size) } \\
25 \text { out of } 26 \text { patients from the Treatment Group while } 7 \text { out of } 23 \text { patients from the Control Group had spontaneous stone } \\
\text { passage with } 8-10 \mathrm{~mm} \text { stone size } \\
\text { The Average stone passage time for } 6-7 \mathrm{~mm} \text { stone size for the treatment group was } 3.6 \text { weeks while it took } 10-16 \text { weeks for } \\
\text { the control group } \\
\text { Average Stone passage time for } 8-10 \mathrm{~mm} \text { stone size for the treatment group was } 5.1 \text { weeks while it took } 14 \text { weeks for the } \\
\text { control group }\end{array}$ \\
\hline
\end{tabular}

Table 8. Risk of Bias Table for Vergara (Unpublished)

\section{Bias}

Random sequence generation (selection bias)

Allocation concealment (selection bias)

Blinding of participants and personnel (performance bias)

Blinding of outcome assessment (detection bias)

Incomplete outcome data (attrition bias)

Selective reporting (reporting bias)

Other bias

\section{Authors' judgement Support for judgement}

Low risk

High risk

High risk

Unclear risk

Low risk

Low risk

Unclear risk
Use of table of random numbers

Open Label Study (Tablets were not concealed)

Personnel and Patients were not blinded

Open Label study increases detection bias

Proper documentation of attrition was done

All data outcomes were measured and reported. N/A 


\section{Appendix III. Summary of Findings}

Table 9. Sambong tablets compared with placebo for urinary tract stones

\begin{tabular}{|c|c|c|c|c|}
\hline \multicolumn{5}{|l|}{$\begin{array}{l}\text { Patient or population: } 15-65 \mathrm{y} / 0 \\
\text { Settings: Ambulatory setting } \\
\text { Intervention: Sambong tablet } \\
\text { Comparison: Placebo }\end{array}$} \\
\hline \multirow{3}{*}{ Outcomes } & \multicolumn{2}{|c|}{ Illustrative comparative risks* $(95 \% \mathrm{Cl})$} & \multirow{3}{*}{$\begin{array}{l}\text { No. of } \\
\text { Participants } \\
\text { (studies) }\end{array}$} & \multirow{3}{*}{$\begin{array}{c}\text { Quality of } \\
\text { the evidence }\end{array}$} \\
\hline & Assumed risk & Corresponding risk & & \\
\hline & Placebo & Sambong & & \\
\hline $\begin{array}{l}\text { Radiographic evidence of decrease } \\
\text { in size or number of stones }\end{array}$ & $\begin{array}{l}5.26 \% \text { had evidence of decrease } \\
\text { in size of urinary tract stones }\end{array}$ & $\begin{array}{l}\text { 63.64\% had evidence of decrease } \\
\text { in size of urinary tract stones }\end{array}$ & 41 (2 studies) & $\underset{\text { low }}{\oplus \ominus \ominus}$ \\
\hline $\begin{array}{l}\text { Increase or complete } \\
\text { passage of stone/s }\end{array}$ & $\begin{array}{l}5.26 \% \text { in the placebo group } \\
\text { had increase or complete } \\
\text { passage of stone/s }\end{array}$ & $\begin{array}{l}73.91 \% \text { in the Sambong group } \\
\text { had increase or complete } \\
\text { passage of stone/s }\end{array}$ & 42 (2 studies) & $\underset{\text { low }}{\bigoplus \oplus \ominus \ominus}$ \\
\hline $\begin{array}{l}\text { Disappearance or reduction } \\
\text { of signs and symptoms }\end{array}$ & $\begin{array}{l}36.84 \% \text { in the placebo group } \\
\text { had disappearance or reduction } \\
\text { of signs and symptoms }\end{array}$ & $\begin{array}{l}78.26 \% \text { in the Sambong group } \\
\text { had disappearance or reduction } \\
\text { of signs and symptoms }\end{array}$ & 42 (2 studies) & $\underset{\text { low }}{\oplus \oplus \ominus}$ \\
\hline
\end{tabular}

${ }^{*}$ The basis for the assumed risk (e.g. the median control group risk across studies) is provided in footnotes. The corresponding risk (and its 95\% confidence interval) is based on the assumed risk in the comparison group and the relative effect of the intervention (and its $95 \% \mathrm{Cl}$ ).

High quality: Further research is very unlikely to change our confidence in the estimate of effect.

Moderate quality: Further research is likely to have an important impact on our confidence in the estimate of effect and may change the estimate.

Low quality: Further research is very likely to have an important impact on our confidence in the estimate of effect and is likely to change the estimate.

Very low quality: We are very uncertain about the estimate.

Table 10. Adverse events observed in sambong tablets

Patient or population: $15-65 \mathrm{y} / \mathrm{o}$ with Urinary tract stones $>5 \mathrm{~mm}$ in size or with radiographic evidence of Urinary tract stones

Settings: Ambulatory setting

Intervention: Sambong tablet

Comparison: Placebo

\begin{tabular}{|c|c|c|c|c|}
\hline \multirow{3}{*}{ Outcomes } & \multicolumn{2}{|c|}{ Illustrative comparative risks* $(95 \% \mathrm{Cl})$} & \multirow{3}{*}{$\begin{array}{c}\text { No. of } \\
\text { Participants } \\
\text { (studies) }\end{array}$} & \multirow{3}{*}{$\begin{array}{c}\text { Quality of } \\
\text { the evidence }\end{array}$} \\
\hline & Assumed risk & Corresponding risk & & \\
\hline & Placebo & Sambong & & \\
\hline Epigastric Pain & $\begin{array}{l}0 \% \text { in the placebo group } \\
\text { had epigastric pain. }\end{array}$ & $\begin{array}{l}8.33 \% \text { in the Sambong group } \\
\text { had epigastric pain. }\end{array}$ & 23 (1 study) & $\underset{\text { very low }}{\oplus \Theta \Theta \Theta}$ \\
\hline Tinnitus & $\begin{array}{l}9.09 \% \text { in the placebo group } \\
\text { had tinnitus. }\end{array}$ & $\begin{array}{l}0 \% \text { in the Sambong group } \\
\text { had tinnitus. }\end{array}$ & 23 (1 study) & $\begin{array}{c}\oplus \ominus \ominus \Theta \\
\text { very low }\end{array}$ \\
\hline
\end{tabular}

${ }^{*}$ The basis for the assumed risk (e.g. the median control group risk across studies) is provided in footnotes. The corresponding risk (and its 95\% confidence interval) is based on the assumed risk in the comparison group and the relative effect of the intervention (and its $95 \% \mathrm{Cl}$ ).

High quality: Further research is very unlikely to change our confidence in the estimate of effect.

Moderate quality: Further research is likely to have an important impact on our confidence in the estimate of effect and may change the estimate. Low quality: Further research is very likely to have an important impact on our confidence in the estimate of effect and is likely to change the estimate. Very low quality: We are very uncertain about the estimate. 